\title{
UNHCR and Current Challenges in International Refugee Protection
}

\author{
Ninette Kelley and Jean-Francois Durieux
}

\begin{abstract}
The international refugee protection regime has had both a successful and a troubled history. It has succeeded in providing international protection to millions of refugees when their own States have been unable or unwilling to do so. Despite this considerable achievement, the regime has at times failed to solve serious refugee protection problems and has not been able to effect durable solutions for many of the world's refugees. This essay examines the current challenges to the regime from the perspectives of those most affected by them, recognizing that many of these challenges are not new. It examines how UNHCR's mandate and activities have expanded to meet the larger number and diverse needs of those under its care. As well, it reviews the recent initiatives launched by UNHCR to strengthen international protection for refugees and expand the availability of durable solutions through enhanced multilateral cooperation.
\end{abstract}

\section{Résumé}

Le régime international de protection des réfugiés a con$n u$ des hauts et des bas. D'une part, il a réussi à fournir la protection de la communauté internationale à de millions de réfugiés lorsque leurs propres pays étaient incapables ou pas disposés à le faire. En revanche-et en dépit de cet accomplissement majeur - le régime n'a parfois pas réussi à résoudre de sérieux problèmes de protection de réfugiés et n'est pas parvenu à mettre en place des solutions durables pour un grand nombre de réfugiés de par le monde. Cet essai se penche sur les défis confrontant le régime en ce moment-ci, examinant les choses du point de vue de ceux qui en sont les plus affectés, et tout en reconnaissant qu'en réalité beaucoup de ces défis ne datent pas d'hier. Il examine la façon dont le mandat et les champs d'activités de l'UNHCR se sont élargis pour satisfaire les besoins hétérogènes et les nombres grandissants de ceux dont il s'occupe. En même temps, il passe en revue les récentes initiatives lancées par l'UNHCR dans le but de renforcer la protection internationale des réfugiés et d'élargir, à travers une meilleure coopération multilatérale, la gamme de solutions durables disponibles.

\section{Introduction}

${ }^{t}$ $\mathrm{t}$ is now almost commonplace to question the effectiveness of the international regime for protecting refugees. Some claim that the 1951 Convention Relating to the Status of Refugees (1951 Convention) and the 1967 Protocol are not able to adequately address the magnitude and the complexity of refugee protection needs. Regional and national institutions, laws, practices, and policies concerned with refugees, which also make up the refugee regime, are as well the focus of disapproval. Yet the critical spotlight on the refugee regime is neither new nor a reflection of recent realities.

The fact is that challenges to the international refugee protection regime are a persistent feature of the history of refugee movements and generally involve serious concerns about the limits of State responsibility for those who are neither citizens nor invited guests. One can look to almost any major refugee movement over the past century and find that debates over the need and the means to provide protection were animated by many of the same anxieties that are echoed most frequently today. These include legitimate, although at times conflated, concerns over preserving sovereignty, maintaining social and economic stability, and preventing threats to national security. 
People fleeing persecution disregard international boundaries. Large numbers can overwhelm neighbouring States, many of which do not have adequate resources to fully care for the basic needs of their own nationals, let alone for foreigners. Refugees can strain the patience of more distant States, who question why their responsibilities should extend to those who have transited other countries, whose identities are not known, and who are suspected of using the asylum process to simply seek better economic opportunities.

The international refugee protection regime therefore can be characterized as one that is frequently in a state of crisis. While the regime is rooted in 1951 Convention and 1967 Protocol, these instruments do not, nor were they intended to, meet the full panoply of refugee protection needs. What they established, and continue to provide are important baseline principles for individual international protection and collective responsibility sharing. But they do not directly address, or offer a framework for meeting, other protection imperatives. These include the need for comprehensive approaches to large-scale and protracted refugee situations, more equitable and principled co-operation concerning secondary refugee flows, and expanded opportunities and support for durable solutions. The absence of clear and principled multilateral commitments to address these problems is very much at the heart of the current challenges to international refugee protection.

Given these gaps, other approaches are needed, not to replace the international refugee treaty legislation, but to supplement it, notably drawing from the basic human rights principles underlying it. Without them, State willingness to provide protection and solutions to refugees, and in particular to accept the basic principles set out in the international refugee instruments, may be seriously undermined.

This essay examines the responsibilities of the United Nations High Commissioner for Refugees (UNHCR) and how they have increased to meet the changing patterns and complex needs of global population displacements. It looks at the current challenges to refugee protection, seen from the perspectives of those most affected by them. The final section reviews how UNHCR has responded to those challenges, with particular focus on the Office's efforts to strengthen international protection for refugees and expand the availability of durable solutions through enhanced multilateral co-operation.

\section{UNHCR and the International Protection Regime}

The 1950 Statute setting out the mandate of the newly established Office of the UNHCR, and the 1951 Convention, reflect the dominant concern in Europe at the time of their creation. This was to provide protection and solutions for
post-World War II refugees. ${ }^{1}$ Both documents adopt a relatively narrow definition of "refugee" as a person who, as a result of events occurring before 1951, is outside his or her country because of a well-founded fear of persecution for reasons of race, religion, nationality, political opinion, or membership in a particular social group. ${ }^{2}$ In addition to the time limitation, the Convention definition, and that found in the UNHCR Statute, had an optional geographic limitation (to those fleeing events in Europe). The time limitation was lifted in the 1967 Protocol. Only a few States have retained a geographic limitation.

The 1951 Convention was, and remains, focused on refugee status based on an individual fear of persecution for reasons of the enumerated grounds. It sets out fundamental principles of international protection, which, notwithstanding its initial limited intent, has provided the framework for ensuring the recognition of refugee status and attendant rights contained therein to millions of refugees over the last half century. These rights include the right to seek asylum in signatory countries, to have asylum claims determined without discrimination, not to be penalized for having entered an asylum country without prior authorization, not to be returned to persecution, and not to be expelled unless in exceptional circumstances necessary for reasons of national security or public order. The Convention also enumerates a broad array of civil, political, social, and economic rights to be accorded to refugees in the territory of a signatory State. ${ }^{3}$

Given the context of its creation, and its initial geographic and time-limited intent, it is not surprising that the Convention does not address all refugee protection needs. In fact, more surprising is that it has responded as well as it has to a broader set of circumstances than initially intended. The persecution of women, of indigenous populations, and of individuals on account of their sexual orientation, and persecution by non-State authorities have been recognized under the Convention definition, thereby extending international protection to them in a manner consistent with today's broader human rights awareness but beyond what would have been envisaged in 1951.

In this regard the development of human rights law more generally over the past fifty years has complemented and augmented the protections afforded under the 1951 Convention, refugees being entitled to the broad range of general human rights protections provided to all individuals in international and domestic human rights instruments as well as the specific protections accorded under the Convention. Together these rights have enriched the international refugee protection regime, underscoring the need for and informing the content of principled responses to refugee needs. 
UNHCR's mandate has also been transformed. Originally the Office was intended to be a temporary institution with responsibilities extending only until durable solutions for World War II refugees had been secured. However, as conflicts between and within nations persisted, producing more refugees, the General Assembly continued to extend the duration of UNHCR's mandate. It also expanded the content of it. Successive General Assembly and Economic and Social Council (ECOSOC) resolutions broadened UNHCR's mandate, calling on the Office to assist refugees fearing individual persecution as well as those fleeing generalized violence and also "others of concern" because of their need of international protection. ${ }^{4}$ These include former refugees who have returned to their countries (returnees), specified groups who have been displaced within their own countries due to armed conflict or generalized violence (internally displaced persons or "IDPs") and people who are stateless or whose nationality is disputed. ${ }^{5}$

The widening of categories of persons of concern to UNHCR and for which it has protection responsibilities has been accompanied by an expansion of the protection activities the Office is engaged in. Mandated to provide international protection to refugees and to seek permanent solutions to their plight, UNHCR initially focused on identifying refugees within Europe, primarily World War II refugees and refugees fleeing communism, and securing for them resettlement opportunities in the West. Subsequently, massive population displacements arising from conflicts throughout Africa, Asia, and Latin America called for more varied responses in circumstances where the causes of flight and the international protection needs attending them were more complex.

The scope of UNHCR's international protection operations accordingly expanded, embracing a myriad of activities over a number of areas. These include the provision of emergency humanitarian relief assistance and long-term care and maintenance; material and logistical support to returnees; programs to promote refugee protection principles and human rights; more targeted interventions on behalf of refugee women and children; efforts to build and/or enhance democratic governance and conflict prevention; and efforts to promote the channelling of development assistance to benefit refugees, returnees, and local communities.

Once it was a Eurocentric institution, with an initial budget of US $\$ 300,000$, focused primarily on the local integration and voluntary repatriation of 400,000 European refugees. Today it has 153 offices operating in sixty-nine countries throughout the world, with approximately 5,000 staff and a budget of just under US $\$ 1$ billion, assisting over 20 million refugees and others of concern
The broadening of UNHCR's international protection activities therefore has been a result of the rise in the number of refugees and others of concern under its care globally, and a response to the varied environments in which it works and the diverse protection needs of those under its mandate. It also reflects the development of human rights law and standards. The protection of refugees has a legal as well as physical dimension. The rights to fair treatment upon reception, not to be returned to prospective persecution, and other recognized rights to adequate health, housing, food, shelter, education, and durable solutions are safeguarded through UNHCR's wide-ranging legal and material assistance activities.

\section{Current Challenges}

The expansion of UNHCR's responsibilities and activities and the adaptability of the 1951 Convention suggest that the international refugee protection regime has responded well to the growing demands placed upon it. But these developments do not tell the whole story. The effectiveness of the international protection regime must also be measured by the pattern of refugee movements, the number of refugees who remain at risk and/or without durable solutions, and the willingness of States to admit asylum seekers, recognize and accord rights to refugees within their communities, and share responsibility for refugee protection with neighbouring or more distant States that shoulder a disproportionate burden. Using these indicators, the picture is far from a perfect one.

The total refugee population rose from a few million refugees in the 1970s to over 10 million by the mid-1980s, skyrocketing to more than 18 million over the next decade. Recent figures indicate that in 2003 the number of refugees and others of concern to UNHCR was 20.6 million, "roughly one out of every 300 persons on earth."

The burgeoning numbers of individuals in need of international protection around the world is a consequence of the grave human rights abuses that have characterized the wars and communal violence that have marked the past quarter century. They also bear witness to a global community incapable, and at times unwilling, to interfere to prevent the violations that have sparked so many of the world's major refugee tragedies.

The rise in the number in the world's refugees is one part of the troubled picture of international refugee protection. The other side of the picture is how such refugee populations have been received. Like art, this evaluation is largely a matter of perspective.

\section{Industrialized Countries}

Industrialized countries frequently claim that their historic generosity towards refugees, and confidence in the relevance 
of the 1951 Convention and 1967 Protocol, have been shaken by the enormous increase in the demands made upon their asylum system by migrants of mixed motivations. They point to the rapid rise in asylum applications beginning in the 1980s, from approximately 140,000 in 1982 to over six times that number by 1992 when close to 860,000 asylum applications were made. ${ }^{7}$ Although these figures have decreased significantly since then, ${ }^{8}$ some government officials and sections of the media continue to paint a picture of overwhelming numbers swamping national systems and straining social structures.

Commentators point out that it is not just the number of asylum seekers that has led to this loss of confidence in the international protection regime. It is also a reflection of a shift in strategic interests, a radical change in the ethnic background of asylum-seekers, and a rise in clandestine means of arrival. Many refugees in the West during the first forty years of the 1951 Convention were escaping communist regimes and so received a ready welcome. The end of the Cold War removed this strategic aspect of refugee protection. It was also accompanied by a rapid increase in the numbers of asylum seekers coming from further afield than ever before.

The increase in the number of asylum seekers from more distant States reflects not only the violence and conflict which have led to massive population displacements but also the greater ease of travel. Improved transportation and communication linkages, the expansion of transnational social connections, and the growth of illegal trafficking and smuggling networks have made international travel more accessible both to economic migrants and to refugees. They also cause increasing unease among States distressed at the growing numbers of unauthorized arrivals and the expansion in the criminal networks that make such arrivals possible.

Those who arrive unlawfully can be motivated by a number of concerns, including: a need for international protection (to seek safety from persecution and/or generalized violence); economic interests (to improve their quality of life); social reasons (family reunification); and/or a mixture of these concerns. Fair and effective refugee status determination procedures are able to identify refugees within broader mixed migration flows. Where these are lacking, delays and backlogs develop, as in many western States. Combined with large numbers of asylum seekers without proper documents, they lead to growing frustration, intolerance, and allegations that most asylum seekers are simply using the asylum system to "jump the queue," bypassing regular admission procedures and gaining an unfair advantage over more law-abiding and qualified immigration applicants.

Adding to these complaints are the high costs associated with supporting inefficient refugee status determination and appeals procedures, funding the social services afforded to asylum seekers and meeting the expenses of enforcement mechanisms used for detention and removal purposes. The argument is frequently made that money would be far better spent providing assistance to refugees in their own regions - regions that are, however, disproportionately affected by mass refugee flows and which have limited resources to meet the protection challenges involved

Increasingly, the response of many industrialized States has been to implement measures to prevent entry into their territories and to restrict access to their asylum procedures (for example, by visa requirements, sanctions against carriers that undocumented asylum seekers have used, interdiction of asylum seekers en route, application of the safe-third-country concept) rather than to concentrate on improving their refugee determination procedures. Other initiatives to reduce incentives to request asylum include detention, reduction in welfare benefits, prohibitions on wage-earning employment, and restrictions on the ability of families to reunite.

In their efforts to bring asylum claims to more manageable numbers, States have negotiated agreements with transit countries and other countries in which asylum seekers have resided, for the readmission of asylum seekers without ensuring that basic protection guarantees will be met. In addition, restrictive interpretations of the Convention definition and a narrow application of rights within the Convention are becoming a disturbing trend.

There is a tendency to exaggerate the change in attitudes towards refugees in recent years. Many studies have shown that the admission of refugees has always raised fairly contentious issues, and that limiting the application of the 1951 Convention has long been debated within asylum countries in the industrialized world. Having said that, it is true that today there are more vigorous attempts to restrict access and to more narrowly define the application of the Convention than ever before.

Some claim that declining numbers of annual asylum applications bear witness to the success of these endeavours. Others point out that this phenomenon is directly related to the resolution of significant refugee situations, most notably in Afghanistan, Kosovo, and Bosnia, and the consequent reduction of the number of asylum seekers from these countries. What is undisputed is that annual asylum applications in industrialized countries have been in decline, and exaggerated claims to the contrary are not born out by the evidence. From a historically high number of annual asylum applications made in industrialized countries in 1992, they rapidly fell, reduced to over half that amount by mid-decade. While the numbers have since 
fluctuated, they have consistently been 30 per cent lower than the peak in 1992. Recent figures indicate that the annual levels have significantly dropped again. Last year some 460,000 asylum claims were made in industrialized countries, approximately 20 per cent fewer than in 2002 and 25 per cent below the 2001 level. $^{9}$

Although the numbers have declined, negative attitudes toward asylum seekers continue to hold considerable currency, often inflamed in the context of elections where promises to reform the asylum system are a popular means to solicit public support. Opinions are frequently fuelled by misconceptions about the reasons why refugees flee and assumptions that refugees and asylum seekers are nothing but a burden on host societies. Arguments in favour of restricting the application of the 1951 Convention, and periodic calls for forgoing it altogether, continue to rattle the international protection regime.

Among the misconceptions about asylum seekers is that they are not credible, as evidenced by their use of false documents and resort to illegal entry to make their asylum claims. The absence of authentic identity documents poses problems for States that seek to be assured, with a reasonable degree of certainty of the identity of asylum applicants. Yet as recognized within the 1951 Convention itself, those fleeing persecution often are unable to get the required documents to travel openly to another State and therefore should not necessarily be prejudiced for failing to do so. Credible evidence short of documentation can confirm the applicant's identity and in some cases the absence of identity documents may in fact corroborate the claim.

The hard necessity of travelling illegally, and resorting to smugglers to do so, has only increased with the greater barriers placed in the way of accessing asylum countries. It involves considerable risks to the refugee. Exposed to exploitation and physical hardship en route, they are often indebted for many years to those who have brought them across borders and face the constant risk of violence for failure to pay. Many do not reach their intended destination and are left stranded in other countries, forcing them to resort to other criminals to protect them from detection and to assist them in moving onward.

Another misconception concerns the impact of the increased ease of transnational travel, which is often perceived as having a greater effect on the global distribution of refugees than is born out by the evidence. While improvements in communication and transportation have in part accounted for increases in the number of asylum claims made in industrialized countries, they have not had a noticeable impact on the distribution of refugees worldwide. The fact remains that most of the increase in the global refugee population continues to be borne by developing countries, where over 65 per cent of the world's refugees are found.

\section{Developing Countries}

And here is where perspectives most noticeably collide. While industrialized countries complain about the number of refugees crossing their borders annually, host countries in the developing world are increasingly disillusioned with the absence of effective burden sharing. ${ }^{10}$ Here the complaint is not so much that international protection has stopped functioning properly, but that in this regard it never functioned adequately at all. They argue that meeting the burden of meeting the protection needs of refugees has always primarily rested on developing countries whose fragile economies, environments, and social and political stability have been threatened in the process of providing refuge to millions of refugees.

Serious concerns about national security have also accompanied many refugee flows in the developing world, when the conflict that precipitated their flight crosses borders as well. This has significantly threatened the lives and safety of both refugees and local populations. The militarization of the large refugee camps in eastern Zaire following the genocide in Rwanda in 1994 is a particularly dramatic example, ${ }^{11}$ although not an isolated one. Moreover, confronted with the challenges of meeting the needs of their own populations, including high rates of unemployment, environmental degradation, and HIV/AIDs - often in the face of declining development assistance - a number of these countries question the logic of having to be primarily responsible for refugees on the basis of proximity alone.

Humanitarian assistance, developing countries say, is often dominated by foreign policy concerns of donor States and influenced by media attention, rather than driven impartially and provided in proportion to the severity of the need.

They point to long-standing crises that have been relatively ignored, such as the Tindouf refugee camps in southwestern Algeria, where refugees from Western Sahara have been living for over twenty-five years and where over 165,000 refugees frequently face acute shortages of food. Constant underfunding of UNHCR care and maintenance programs in other parts of Africa underscore similar concerns.

The response to the Kosovo crisis in 1998-99 is another often-cited example. The international response to the plight of the nearly 1 million Kosovo Albanian refugees who had fled Serbian military repression and later NATO bombardment contrasted starkly with the assistance provided to African refugee emergencies at that time. Veteran aid 
workers were among the first to draw the comparisons. In African refugee camps, where water was scarce and sanitation facilities basic, and in areas where one doctor was available for every 100,000 people, thousands of refugees died daily from cholera and other public health diseases. Per capita expenditure for Kosovar refugees in the Balkans, it was alleged, was over ten times that spent on African refugees. Shelter for refugees in Macedonian camps was considerably better than in Africa, water plentiful, food rations varied, medical assistance available (one doctor for every 700 refugees), and death from public health emergencies virtually non-existent. ${ }^{12}$

The point is made that the tremendous outpouring of Western support for Kosovar refugees was in part due to the fact that westerners could identify with the Kosovars, who looked similar and had comparable lifestyles, unlike most refugees from the developing world. But it is also argued that geopolitical considerations, including the desire to arrest an outpouring of refugees into Europe and to prevent destabilization of the region, were paramount concerns. Nor, it is said, was Kosovo a unique case of strategic imperatives dictating the size of humanitarian interventions.

The generous humanitarian support for the repatriation effort to East Timor in 1999 and 2000 has also been attributed to foreign policy concerns driving the humanitarian agenda rather then the needs of refugees and those countries which host them. Concern for stability in the region, and in particular the strong desire of Asian and Western countries to ensure a peaceful transition to independence in East Timor without destabilizing Indonesia and/or disrupting the flow of oil and the security of shipping lanes in the Timor Gap, were key motivations. The point is made that had humanitarianism been the primary concern, "there would have been considerably more donor action during the previous 25 years, during which an estimated 200,000 Timorese died" while under Indonesian occupation. ${ }^{13}$

A similar point is now made in regard to Afghanistan and Iraq, which have been the focus of considerable aid post 9/11. African governments have pointed out that, while the countries within their continent host two-thirds of the world's refugee camps, UNHCR care and maintenance programs there are inadequately funded, so that they are unable to meet minimum standards, let alone provide refugees with a means for decent self-reliance. ${ }^{14}$ They claim that money moving to high-profile emergencies like Afghanistan and Iraq draws attention and funding away from just as pressing problems in Africa and elsewhere.

Developing countries further allege that not only is humanitarian aid often disproportionately distributed but the durable solutions promoted by donor counties are likewise imbalanced. They question why they should they be re- quired to keep their borders open to refugees while donor countries are closing theirs, as well as being expected to provide refugees with local durable solutions. ${ }^{15}$ Where, they ask, is the symmetry in the frequent demand that resettlement of a relatively small percentage of refugees be accompanied by enhanced opportunities for the local integration of a considerably larger proportion of the refugee population ${ }^{16}$ The capacities of poor countries to integrate their refugee populations, when faced with enormous problems resulting from their own underdevelopment and related social tensions, cannot, they argue, be equated with the capacities of developed countries to significantly enhance the number of refugees they resettle. ${ }^{17}$ To suggest otherwise is, they claim, to engage in burden shifting and not burden sharing.

Many countries that host significant numbers of refugees have been doing so for prolonged periods of time. The lack of support in sharing this responsibility has led to a hardening of attitudes towards refugees and weariness with playing host when the costs are so significant. Over the years, developing countries with large refugee populations have cited their need to preserve national security as a reason for their declining commitment to protecting refugees at all costs and for the imposition of tighter border controls, forced repatriation, the roundup of refugees and their confinement in camps, and a refusal to consider the integration of refugees in local communities, which many host governments believe will root refugees there permanently and encourage others to come and reap similar benefits.

\section{Refugees and Asylum Seekers}

In the midst of State wrangling over the extent of their responsibilities towards refugees, refugees face a multitude of serious protection concerns. In many ways these constitute the real crisis in today's protection regime. UNHCR annually provides a Note on International Protection to the Executive Committee of the High Commissioner's Programme. There is a disturbing constancy reflected in these Notes in the severe protection problems that have persisted in recent years.

These include high levels of deportation and expulsion from asylum States to territories where the refugees' lives or freedom are threatened. Unacceptably high levels of violence and intimidation of refugees are also consistently reported and are particularly prevalent where large numbers of refugees are confined to camps. These include violence at the hands of armed combatants within and outside the camps as well as harassment, exploitation, and attacks by national authorities and local populations. Other forms of serious harm such as domestic violence, sexual assault, and rape are often endemic to large and protracted situ- 
ations, as are a host of other social ills born of the frustration, dependency, and despondency of prolonged confinement.

Refugees and asylum seekers in both large-scale influxes and individual asylum processes face discrimination on account of their race, religion, and national or ethnic origin. This can range from the denial of civil rights concerning employment, education, and access to social services to exclusion from asylum procedures and removal from the asylum country without their applications having been considered.

In addition to these immediate protection concerns, far too many refugees are in a state of limbo with no durable solutions in sight. Two-thirds of the 5 million refugees in Africa, for example, have been in exile for over five years and are confined to camps or organized settlements, many of which are located along insecure borders, vulnerable to attack. They are commonly in remote, environmentally inhospitable areas, which do not receive development assistance. These protracted refugee situations, where prospects for durable solutions are not yet in sight, are another major challenge to the international refugee protection regime.

Even positive trends face significant trials in terms of sustainable protection. In 2003, UNHCR assisted approximately 3.5 million people to return home, the majority of whom were Afghan refugees from neighbouring Pakistan and Iran. Other sizable returnee populations included refugees returning to Angola, Sierra Leone, Burundi, Bosnia and Herzegovina, Sri Lanka, and the Russian Federation.

The challenges involved in these repatriation exercises are enormous, as the spotlight on Afghanistan makes abundantly clear. But Afghanistan is not an exceptional case. In Angola for example, a country devastated by civil war that displaced 4 million people, malnutrition is widespread and mortality and morbidity rates are very high. Close to 3 million refugees and IDPs have returned to their places of origin, and over 150,000 more are anticipated in 2004. They are returning in extraordinarily difficult circumstances. There is little infrastructure for the provision of basic health, education, and water delivery services. Poor roads and destroyed bridges hinder travel throughout much of the country, as does the presence of landmines and unexploded ordnance which prevents the resumption of farming in many areas, threatening food security.

Return, therefore, is not itself a guaranteed durable solution. The stability of the process requires a host of interrelated activities that not only provide immediate material assistance necessary for initial reintegration but link these to other sustainable development activities over the longer term to the benefit of returnees and local residents. This requires sustained and co-operative commitment by a host of actors, no small challenge in complex environments with limited funds allocated for development worldwide. Yet it is a challenge that must be met to ensure the prospects for durable peace and limit the risks of further displacements.

\section{UNHCR and New Approaches to International Refugee Protection}

\section{Global Consultations on International Protection}

In 2001, on the occasion of the fiftieth anniversary of the 1951 Convention, UNHCR launched the Global Consultations on International Protection. This was a two-year process of ministerial and expert meetings designed to take stock of the developments in international refugee protection over the past half century, to address the gaps in the international protection framework, and to map out a plan of future action.

The Global Consultations were organized along three parallel "tracks." The first culminated in a meeting of State parties to the 1951 Convention and 1967 Protocol in December 2001. The result was a Declaration of States Parties, the first in the history of the 1951 Convention. In the Declaration, States reaffirmed their commitment to implement their obligations under the 1951 Convention and 1967 Protocol, recognized the importance of other human rights instruments in the protection of refugees, and stressed the need to strengthen the implementation of these instruments as well as to work co-operatively to achieve durable solutions for refugees. The Declaration was significant in that it was a formal expression of State support for the existing framework of refugee protection and the political will to do better.

The "second track" of the Consultations was a series of expert roundtable discussions attended by government officials, academics, judges, NGOs, and other interested parties. These focused on issues pertaining to aspects of the 1951 Convention which were subject to varying interpretations and for which greater clarity and consistency were required. Among the topics canvassed were the cessation and exclusion clauses of the Convention, the principle of non-refoulement and the internal flight alternative, the meaning of "particular social group" and gender-based persecution, the consequences of illegal entry, and the right of family unity. ${ }^{18}$ Each roundtable issued conclusions that identified areas of common ground and provided interpretative guidance.

The "third track" meetings were held amongst members and observers of UNHCR's Executive Committee. These focused on issues not adequately covered by the 1951 Convention such as registration, reception, interdiction, and return of asylum seekers, the protection of refugees in mass-influx situations, the protection of women and child refugees, and how to enhance the prospects of durable 
solutions through voluntary repatriation, local integration, and resettlement. Parallel regional meetings were held along similar themes as a way to ensure inclusive and broad input to the process from around the world.

The Global Consultations were an impressive and successful attempt to foster open and informed dialogue among those who did not necessarily view the content of international protection, or State responsibility to provide it, through the same lens. The conclusions arising from the roundtable discussions did not resolve all the points of interpretative divergence, but they do map out points of agreement arrived at and recognized within the process of open discourse that the Consultations provided. They go a considerable distance to encourage and support more consistent application of international refugee protection principles and have formed the basis for a new series of UNHCR Guidelines on International Protection. ${ }^{19}$

The Global Consultations also highlighted areas that require further action to bridge the gaps in the international refugee protection regime, to more equitably share the burdens and responsibilities of protecting large numbers of refugees, and to provide enhanced opportunities for durable solutions. These became the blueprint for setting priorities, priorities which are now reflected in the Agenda for Protection.

\section{Agenda for Protection}

The Agenda for Protection, jointly adopted by States and UNHCR in 2002, and welcomed by the United Nations General Assembly that same year, is a comprehensive plan of action for UNHCR, governments, NGOs, and other partners. It focuses on international protection activities that can be enhanced by multilateral commitments and co-operation. Specifically, the Agenda focuses on six interrelated goals: (1) strengthening implementation of the 1951 Convention and its 1967 Protocol; (2) protecting refugees within broader migration movements; (3) sharing burdens and responsibilities more equitably and building capacities to receive and protect refugees; (4) addressing security-related concerns more effectively; (5) redoubling the search for durable solutions; and (6) meeting the protection needs of refugee women and refugee children. Each goal has a detailed set of associated objectives and activities necessary for its attainment.

From an operational perspective, it is up to UNHCR, governments, and others who have endorsed the Agenda to set priorities among its multi-layered and multi-year commitments. For its part, UNHCR offices worldwide set priorities based on the protection needs of their particular operations, and annually report back on the activities undertaken to further their objectives. States have been en- couraged to do the same and a number have shown their willingness to do so.

In addition to serving as a plan of action, the Agenda for Protection is also an important gauge against which progress, or lack thereof, in international refugee protection can be measured. To that end, UNHCR's annual Note on International Protection, submitted to the Executive Committee, provides an account of the major protection challenges of the past year and the steps taken to address them. It is one way of holding both the Office and governments accountable for meeting the objectives identified in the Agenda as vital to safeguarding and expanding the international protection regime.

\section{UNHCR 2004 Process}

Near the end of the Global Consultations the High Commissioner launched the "UNHCR 2004" process. This was an internal review of how UNHCR is positioned within the United Nations system and its relationship with States and other partners. The objectives of the process were to strengthen the multilateral support for the Office and to ensure that it is able to meet the challenges affecting the protection of refugees and the provision of durable solutions.

One of the ambitions of the UNHCR 2004 process was to secure a more solid funding base to augment the traditional system of having to rely solely on voluntary contributions, which frequently do not meet annual budgetary needs. The process developed a voluntary funding model for 30 per cent of UNHCR's budget, to be piloted this year. Under this model, the contribution of participating States would be determined according to the UN scale of assessments.

The process was also valuable in other key respects. In particular, it led to a UN General Assembly resolution to strengthen the capacity of the Office to carry out its mandate..$^{20}$ It also led to institutional priority setting, to guide the Office in the coming years. Among the significant aspects of the General Assembly resolution to strengthen the capacity of the Office was the lifting of the time limitation on UNHCR's mandate. Previously the UNHCR's mandate had to be renewed every five years; it now extends until the refugee problem is solved. This will support more strategic and long-term planning of UNHCR activities.

There is a growing need to forge firmer linkages between the many actors that work side by side in areas that have a direct bearing on UNHCR's activities. These include organizations involved in the fields of humanitarian relief, peace and security, human rights, and development. To ensure that refugee concerns are factored into the operations of such agencies, the General Assembly resolution called on relevant UN entities, including the Emergency 
Relief Coordinator, the UN Development Group, and the Departments of Peacekeeping and Political Affairs to include in their planning and programs refugees and other persons of concern to UNHCR.

The UNHCR 2004 process also examined institutional responses to challenges in refugee protection that had been discussed within the Global Consultations. The final report on the process set out a number of priorities for the Office, including implementing the Agenda for Protection, promoting new accessions to the international conventions on statelessness, ${ }^{21}$ ensuring full engagement with other agencies in assisting IDPs and returnees, and greater engagement with NGO partners in operational assessment and planning. ${ }^{22}$

In addition, the report highlighted the importance of multilateral co-operation to ensure that refugees and asylum seekers were protected within broader migration control measures and to realize durable solutions for more refugees. These latter priorities have been taken forward by the Convention Plus initiative launched by the High Commissioner in 2003, just as the UNHCR 2004 process was drawing to a close.

\section{Convention Plus}

Convention Plus is a process that brings States and intergovernmental and non-governmental partners together to reach special agreements to enhance protection of refugees in areas that are not fully addressed by the 1951 Convention and 1967 Protocol. Specifically, it aims to achieve agreements in the following areas: the more strategic use of resettlement for the benefit of a greater number of refugees; the more effective targeting of development assistance to support durable solutions for refugees; and clarification of the responsibilities of States in regard to irregular secondary movements of refugees. Each was highlighted in the Agenda for Protection as in need of further multilateral attention.

Resettlement has long been recognized as an important response to the protection needs of individuals who are at risk. It is also a durable solution for those who can neither return to their own countries nor integrate locally in the country which hosts them. As well, it is a manifestation of burden sharing, particularly when large numbers of refugees are resettled, thereby alleviating the strain their prolonged presence causes the hosting State.

The need to improve resettlement to enhance its benefits was discussed during the Global Consultations and specific actions to do so were set out in the Agenda for Protection. These include expanding resettlement opportunities; enhancing resettlement capacities through increased partnerships with NGOs and other relevant partners; introducing more flexibility into resettlement criteria; and ensuring reset- tled refugees enjoy equality of rights and opportunities in the social, economic, and cultural life of the resettlement country.

Convention Plus provides an opportunity for moving ahead on these commitments. It does so in an inclusive manner so that the interests of refugees, hosting States, resettlement countries, UNHCR, and other partners are appropriately accounted for. But it is more than a process of negotiation, for the goal is to reach an agreed-upon set of undertakings, a generic agreement, that can be relied upon to resolve specific refugee situations. Presently a core group of States has been constituted and a draft agreement circulated for further consideration and negotiation.

Resettlement alone will not provide the promise of a durable solution for the millions of the world's refugees in need of one. For many refugees, returning home in conditions of peace and security is the most desirable alternative. In the interim, achieving self-reliance in a hosting State and local integration there are the next best alternatives. But these solutions require significant State co-operation, assistance, and financial support that focus on the sustainable development goals necessary to make such solutions durable in the long term. And here the refugee protection regime runs into obstacles. In the context of return, returnees have seldom been part of national development planning, and their needs as well as their productive capacities have been overlooked. Beyond initial humanitarian assistance for their return home, returnees too frequently are left without the longer-term assistance necessary for their integration and contribution to their communities. In the absence of opportunities for a sustainable future, they can become a source of instability and/or feel compelled to leave again.

Linking aid and development for refugees hosted by poor States for prolonged periods of time has also been difficult. For most hosting States, sheltering refugees has imposed tremendous economic and environmental costs. While they welcome development assistance, their priorities are to use scarce development aid to assist their own populations. Development assistance for refugees, they argue, should be over and above that they would have received had they no refugees, and should have a clear positive impact on their local communities.

UNHCR has developed the Framework for Durable Solutions for Refugees and Persons of Concern, ${ }^{23}$ which explains the necessity of using development assistance to secure the sustainability of return and, where that is not possible, to increase self-sufficiency of refugees and reduce the costs States shoulder in hosting them. The Framework provides an institutional blueprint for working in partnership with international financial and development partners and UN agencies in the pursuit of durable solutions for refugees. 
Convention Plus aims to take the process further by bringing States and relevant development actors together to discuss and ultimately agree upon a framework of undertakings for using development assistance to support durable solutions for refugees. This would entail reaching common understandings on what have proved to be difficult areas for agreement, such as: in what circumstances will donor States and receiving countries target development aid for the benefit of refugees and/or returnees; how, and to whom, will such funds will be directed; and what principles will guide the application of such assistance?

Like the work on resettlement, this segment of Convention Plus also has a core group, led by facilitating States that are beginning to tackle these difficult issues. The generic agreement which is intended to result from these labours will be a tangible contribution to the work on durable solutions. In fact, States have insisted on linking the work on developing framework principles to pursuing solutions in particular refugee situations, drawing on the latter experience to feed into the work on generic understandings.

The third focus area of Convention Plus deals with the complex problems associated with addressing irregular secondary movements: the movement of refugees and asylum seekers from an initial country of refuge to another country without authorization. States resent the unorderly and unauthorized movements of people, be they refugees or not, for they undermine the sovereign right of each State to control who enters its territory. Decisions regarding those they are willing to admit are in principle based on coherent economic, demographic, and security objectives. People who circumvent admission procedures undermine these objectives and are regarded as flouting the authority of the State.

It is for these reasons that States feel particularly justified in erecting tighter restrictions on entry. But for refugees these restrictions are particularly severe, barring access to protection and/or compelling them, in their search of protection, to turn to the services of smugglers and traffickers, often putting their lives at risk in the process. Moreover, barriers to entry do not solve the problem; rather, they shift it, leaving it to other States to meet the protection needs of refugees refused admission to, or access to the determination procedures of, other States. Experience suggests that not only do these deterrent policies fail to stem the flow of irregular migration but they may in fact fuel it. In the absence of regular migration options, migrants and refugees alike will continue to turn to smugglers and traffickers. This underscores the difficulty of the problem as well as the need to find a way of dealing with it that addresses the legitimate concerns of States and the real protection needs of refugees.
Convention Plus attempts to meet these dual concerns, again by pulling together interested States and other parties to examine the causes of irregular secondary movements and the roles and responsibilities of States in these situations, and to seek solutions to address them. The aim is to arrive at a generic agreement that will more clearly delineate State responsibilities in regard to irregular secondary movements: one that respects the rights and obligations found within the 1951 Convention and 1967 Protocol, and that observes the imperatives for greater multilateral co-operation and responsibility/burden sharing. This will entail reaching agreement on, for example, the criteria for determining State responsibility for examining an asylum request, the conditions under which such responsibility can be transferred to another State, and the principles that govern State responsibility for providing durable solutions.

As with the other strands of the Convention Plus process, the irregular secondary movement strand is being considered by a core group of States and other interested parties. They are pursuing two lines of inquiry. The first involves determining the causes of irregular secondary movements as revealed in case studies. The second is exploring the principles and interests that should govern the assignment of State responsibility. The results of both will inform the drafting of a special agreement later in the process.

One might well wonder how these different processes are linked, beyond being areas highlighted for action in the Agenda for Protection. First, they are all attempts to address serious and persistent gaps in international protection and ineffective responses which are harmful to refugees and an irritant to States in the North and South. Moreover, they are all focused on furthering durable solutions for refugees and, when pursued in tandem, have complementary effects. For example, where refugees move from one State to another in an irregular manner because of a lack of protection or durable solutions in the first asylum country, then strengthening international protection capacities in the first country of asylum and/or offering more opportunities for durable solutions such as through local integration, voluntary repatriation, and enhanced resettlement can reduce the need for onward movements while providing sustainable benefits to refugees and host communities alike.

Similarly, a committed effort to resettle a sizable number of refugees hosted in already overburdened States may lead to greater receptivity to continue to protect and provide secure asylum to those who remain. Even where voluntary repatriation is possible, because peace and stability have been restored, there will always be those refugees who for good reason are unwilling or unable to return. When repatriation operations are pursued in parallel with the provision of other durable solutions for refugees, such as 
resettlement and local integration, States give meaning to their often-professed commitment to international solidarity and burden sharing for the benefit of refugees.

The joining of these approaches is, in fact, the key to effectively resolving long-term refugee situations as recognized in the 2001 Ministerial Declaration, where States committed themselves to "better refugee protection through comprehensive strategies." In the Agenda for Protection, UNHCR is called upon to follow up on this commitment by reviewing all protracted refugee situations, with a view to exploring with States and other partners the feasibility of comprehensive plans of action to bring into play "each of the available durable solutions, to be implemented in close consultation with countries of origin, host countries, resettlement countries, and refugees themselves."

UNHCR has started this process and intends to use the work and State commitment already shown within the context of Convention Plus to design and implement comprehensive plans of action to solve some of the large refugee situations that have been in need of resolution for too long. A few situations have already been identified. For example, UNHCR is in the process of determining how to bring a mix of solutions to the over 100,000 Somali refugees who for more than a decade have been in Kenya and other neighbouring countries. The Office is also working towards comprehensive solutions for displaced Afghans, including the over 1 million who have returned home and are assisted by Office, and the 3 million others in Pakistan and Iran.

\section{Conclusion}

In the fifty-three years of UNHCR's existence, the world has experienced an exponential growth in displaced populations and UNHCR's responsibilities accordingly have expanded to cover a wider range of people in need of protection. UNHCR has had to meet these challenges without a solid funding base and often without firm commitment by States to uphold their international protection responsibilities and to share burdens among each other more equitably.

Recent years have been marked by additional challenges to the international protection regime, but, as well, by deep and broad reflection by UNHCR, States, and other interested actors on how to meet these difficulties. This has resulted in a reaffirmed commitment by States to uphold the principles embedded in the 1951 Convention and 1967 Protocol and to build upon them by joining together to pursue durable solutions for more refugees in a genuine spirit of multilateral co-operation and responsibility/burden sharing.

As significant as these developments are, actions speak louder than words. For its part, UNHCR has taken concrete steps to follow up on the avowed interest of States and others to resolve inconsistencies in the legal application of the 1951 Convention and 1967 Protocol, to foster more interstate and inter-agency co-operation in its ongoing activities, and to work co-operatively on comprehensive plans of action to provide durable solutions to more refugees.

Whether these efforts will bear fruit depends upon a number of factors, not the least of which are UNHCR remaining focused on these priorities and States being willing to give meaning to their commitment to implement them in a manner that does not exclusively advance their own interests. The success of these initiatives requires sacrificing some self-interest in the knowledge that only by doing so can the refugee situation improve and the number needing international protection be reduced.

\section{Notes}

1. The first formal international effort to provide protection for refugees was thirty years earlier when the League of Nations elected Fridtjof Nansen as High Commissioner for Refugees. Nansen was mandated to provide protection for specified groups of refugees, initially Russian refugees and later also Armenian, Greek, Bulgarian, and other groups of refugees.

2. The UNHCR Statute did not include the ground of membership in a particular social group. Guy Goodwin-Gill suggests that this additional ground was part of the 1951 Convention definition to include groups such as landowners, capitalists, and others who may have been at risk of persecution in socialist States. Guy Goodwin-Gill, The Refugee in International Law, $2^{\text {nd }}$ edition, (Oxford: Clarendon Press, 1996), 46.

3 . For example, the same rights as nationals in regard to primary education, access to the courts and national social assistance and welfare, and the most favourable treatment accorded to foreign nationals in regard to wage-earning employment and freedom of association. For a review of these provisions and State practice, see UNHCR, Note on International Protection, Executive Committee of the High Commissioner's Programme, A/AC.96/951, 13 September 2001.

4. An expanded definition of "refugee" was also adopted regionally within the Organization of African Unity (OAU). In 1969, in recognition that the causes of massive refugee displacements were not limited to individual persecution, the OAU adopted a convention that expanded the definition of "refugee" to include not only those fleeing persecution according to the 1951 Convention definition, but also those fleeing violence and conflict and at risk of indiscriminate harm. Subsequently, in 1984, a colloquium of Central American government representatives and jurists also approved a broader definition of "refugee," similar to that contained in the OAU Convention. Known as the Cartagena Declaration, although not legally binding, the definition recommended in it has been incorporated into domestic legislation by some States and used as a matter of practice by others in the region.

5. The legal basis for this is found in paragraphs 3 and 9 of the UNHCR's Statute. Paragraph 3 provides that: "the High Com- 
missioner shall follow policy directives given to him by the General Assembly or the Economic and Social Council." Paragraph 9 states that the "High Commissioner shall engage in such additional activities, including repatriation and resettlement, as the General Assembly may determine, within the limits of the resources placed at his disposal." For a complete compendium of GA and ECOSOC resolutions relating to issues of concern to the UNHCR, see UNHCR, Thematic Compilation of General Assembly and Economic and Social Council Resolutions (Department of International Protection, 2003).

6. UNHCR, Refugees by Number: 2003 . Of this total number, 10.4 million are refugees and 10.2 million are others of concern to the Office.

7. UNHCR, Statistical Yearbook, 2001, 112-13. These figures are taken from thirty-eight industrialized countries in Europe, North America, Asia, and Oceania.

8. For example, they fell to 377,839 in 1997 and have not exceeded 625,000 in any subsequent year. Ibid. and UNHCR, Asylum Applications Lodged in Industrialized Countries: Levels and Trends, 2000-2002, March 2003, 7.

9. UNHCR, Asylum Levels and Trends in Industrialized Countries 2003, 3, 9 .

10. Over 65 per cent of the global refugee population is hosted by developing countries, and more than 30 per cent by the Least Developed Countries (LDC) in the world. UNHCR, Framework for Durable Solutions for Refugees and Persons of Concern, May 2003.

11. For more on this see UNHCR, The State of the World's Refugees 2000, 248-49.

12. For one of the many press reports on the differences, see "Refugee Camps in Africa and Europe Are a World Apart," Los Angeles Times, 22 May, 1999.

13. Ian Smilie and Larry Minear, The Quality of Money: Donor Behavior in Humanitarian Financing (Boston, MA: Tufts University Humanitarianism and War Project, 2003); online: $<$ http://hwproject.tufts.edu/new/pdf/donor_behav.pdf $>$.

14. A point made forcefully by the South African delegation at the first meeting of the High Commissioner's Forum, 21 June 2003.

15. A question passionately posed by Tanzania in the third Committee of the $57^{\text {th }}$ Session of the General Assembly on Agenda Item 104, 13 November, 2002.

16. Ibid.

17. This was stressed by the African Group at the First Meeting of the High Commissioner's Forum, 27 June 2003.

18. The expert papers presented at each roundtable and the Summary Conclusions of those meetings have been published in E. Feller, V. Turk and F. Nicholson, eds., Refugee Protection in International Law: UNHCR's Global Consultations on International Protection (Cambridge: Cambridge University Press, 2003).

19. Five such guidelines have been introduced as of January 2004 on membership in a particular social group, gender-related persecution, cessation, internal flight alternative, and exclusion.

20. United Nations General Assembly Resolution A/RES/58/153, "Implementing Actions by the United Nations High Commissioner for Refugees to strengthen the capacity of his office to carry out its mandate," 22 Dec. 2003.

21. Specifically, the 1954 Convention relating to the Status of Stateless Persons and the 1961 Convention on the Reduction of Statelessness.

22. UNHCR, "Report by the High Commissioner to the General Assembly on Strengthening the Capacity of the Office of the High Commissioner for Refugees to Carry out its Mandate," 20 August 2003, A/AC.96/980.

23. See above, note 10 .

Ninette Kelley is Legal and Policy Consultant, Office of the United Nations High Commissioner for Refugees (UNHCR), Geneva.

Jean-Francois Durieux is Principal Advisor and Head of the Convention Plus Unit, UNHCR, Geneva. Special thanks to Frances Nicholson, Brian Lander, José Riera, and Carina Van Eck for helpful comments on an earlier draft. 